\title{
Subsidence monitoring with TerraSAR-X data in Beijing Central Business District and subway tunnelings, China
}

\author{
Fengkai Li ${ }^{1,2}$, Huili Gong ${ }^{1,2}$, Beibei Chen ${ }^{1,2}$, Mingliang Gao ${ }^{1,2}$, and Chaofan Zhou ${ }^{1,2}$ \\ ${ }^{1}$ College of Resources Environment and Tourism, Capital Normal University, Beijing 100048, China \\ ${ }^{2}$ Key Laboratory of mechanism, prevention and mitigation of land subsidence, MOE, \\ Capital Normal University, Beijing 100048, China \\ Correspondence: Huili Gong (gonghl_1956@126.com) and Fengkai Li (lfkgiser@163.com)
}

Published: 22 April 2020

\begin{abstract}
Land subsidence caused by large-scale engineering construction may damage the surrounding infrastructures and cause huge economic losses in inner-city environments. In this study, we used PS-InSAR technology on 68 TerraSAR-X images to acquire deformation in the Beijing Plain between February 2010 and December 2018. Then, we calculated the additional stress derived from building loads using the method proposed by Boussinesq in the Central Business District (CBD). We found that the depth of influence of additional stresses induced by building loads was $80 \mathrm{~m}$ and that spatial distribution pattern of the land subsidence rate agreed well with the additional stress. We found that the influence range of ground subsidence caused by metro construction is $200 \mathrm{~m}$ at Ciqikou station by analyzing the subsidence rate profile perpendicular to subway line No. 7 and that the maximum land subsidence rate is $23.2 \mathrm{~mm} \mathrm{yr}^{-1}$. Time series analysis of PS around Ciqikou station shows that land subsidence caused by excavation activities mainly occurs in the period of metro construction. Ground deformation rate decreases gradually after $372 \mathrm{~d}$ of subway operation. The results of both cases show that large-scale engineering construction will lead to significant land subsidence which should be considered in future urbanization.
\end{abstract}

\section{Introduction}

Land subsidence is a ground surface response to the development and utilization of underground and above-ground space (Galloway et al., 2016; Castellazzi et al., 2017; Zhou et al., 2019). Land subsidence can cause a series of disaster chains, which often cause large economic losses, such as damage to buildings and infrastructure and rupture of underground pipelines (Amelung et al., 1999; Jiao et al., 2017). Approximately 150 countries and cities in the world have experienced land subsidence, including China (Chen et al., 2017; Gao et al., 2018), Japan (Uchida, 2015; Sato et al., 2006), USA (Buckley et al., 2003), Mexico (Ortega-Guerrero et al., 1999), Italy (Solari et al., 2016; Rosi et al., 2016), and Indonesia (Du et al., 2018; Ng et al., 2012). Nowadays, land subsidence is a global problem, which has aroused the attention of scholars all over the world in recent decades.

As the capital city of China and an international metropolis, Beijing has experienced rapid urbanization. Many high- density buildings and subway lines have been built in Beijing. Land subsidence caused by large-scale construction projects has become an ongoing problem in Beijing, China and other cities (Chen et al., 2015; Zhao et al., 2016; Ge et al., 2016). Jiao et al. (2017) detected land surface deformation in the Central Business District (CBD) of Beijing from 2010-2013 using the PS-InSAR technique and found that there is a positive correlation between building volume and land subsidence rate when the building volume is larger than $3.00 \times 105 \mathrm{~m}^{3}$. Ge et al. (2016) detected subsidence caused by subway tunneling excavation and construction and found that subsidence makes possible damages to the upper buildings and bridges.

Traditional geodetic methods, including global positioning system (GPS) and leveling, haves a very high measurement accuracy but a small monitoring range and high cost (Strozzi et al., 2011; Ferretti et al., 2007), whereas interferometric synthetic aperture radar (InSAR) has the capability to obtain large-scale, long-time series ground deformation informa- 


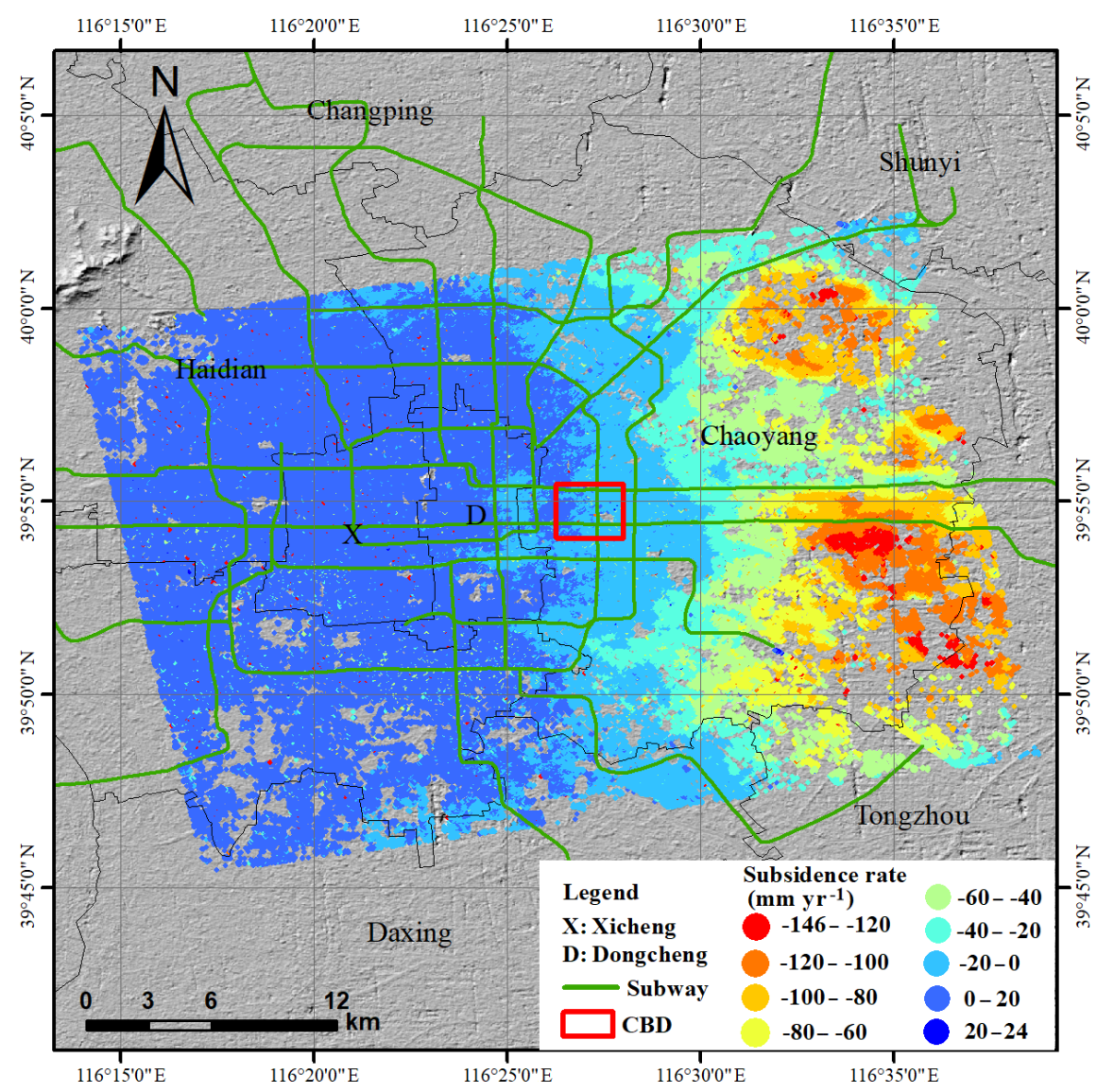

Figure 1. Land subsidence rate map derived from 68 TerraSAR-X images during observation periods between February 2010 and December 2018.

tion with millimeter-scale accuracy in all weather conditions (Galloway and Burbey, 2011). The permanent scatterer interferometric synthetic aperture radar (PS-InSAR) technique, an extension of InSAR, has proven to be an efficient method for monitoring land subsidence in urban areas (Ferretti et al., 2001; Hooper et al., 2004). Based on this advanced technology, we acquired surface deformation information in Beijing by using 68 TerraSAR-X images acquired from February 2010 to December 2018. The first case focused on the subsidence status of CBD and the second case on the tunneling subsidence perpendicular to subway No. 7.

\section{Surface deformation measured by PS-InSAR in Beijing city}

In recent years, Beijing is ongoing a tremendous urban constructions. Many Skyscraper and densely distributed subway lines, city rails have been constructed in this populated city with more than 20 million inhabitants. With subsidence velocity more than 100 to $150 \mathrm{~mm} \mathrm{yr}^{-1}$, land subsidence has become a common geological hazard in Beijing. Compared with uniform land subsidence owning to overexploitation of groundwater, the non-uniform subsidence caused by large- scale construction projects may cause more significant damages to buildings, municipal pipelines, bridges and infrastructures. Meanwhile, subsidence caused by subway tunneling excavation and operation makes possible damages to the upper buildings and bridges. By the end of 2018, a total of 21 metro lines with a total length of $636 \mathrm{~km}$ are operational covering 12 municipal districts in Beijing. In order to study the ground subsidence caused by large-scale engineering construction in Beijing, we obtained surface deformation information from February 2010 to December 2018 (Fig. 1).

\section{Subsidence in Central Business District}

PS-InSAR is an effective tool for monitoring land subsidence especially useful for urban areas because many man-made targets maintain stable scattering characteristics. It is possible to accurate description to the ground targets due to the high resolution.

The CBD located in Chaoyang District covers an area of $2.4 \times 2.5 \mathrm{~km}^{2}$. From 2000 to 2010 , many high buildings were built in the area. According to the data provided by relevant departments, there are 21 buildings that are higher than $100 \mathrm{~m}$. The impact of additional stress derived from build- 


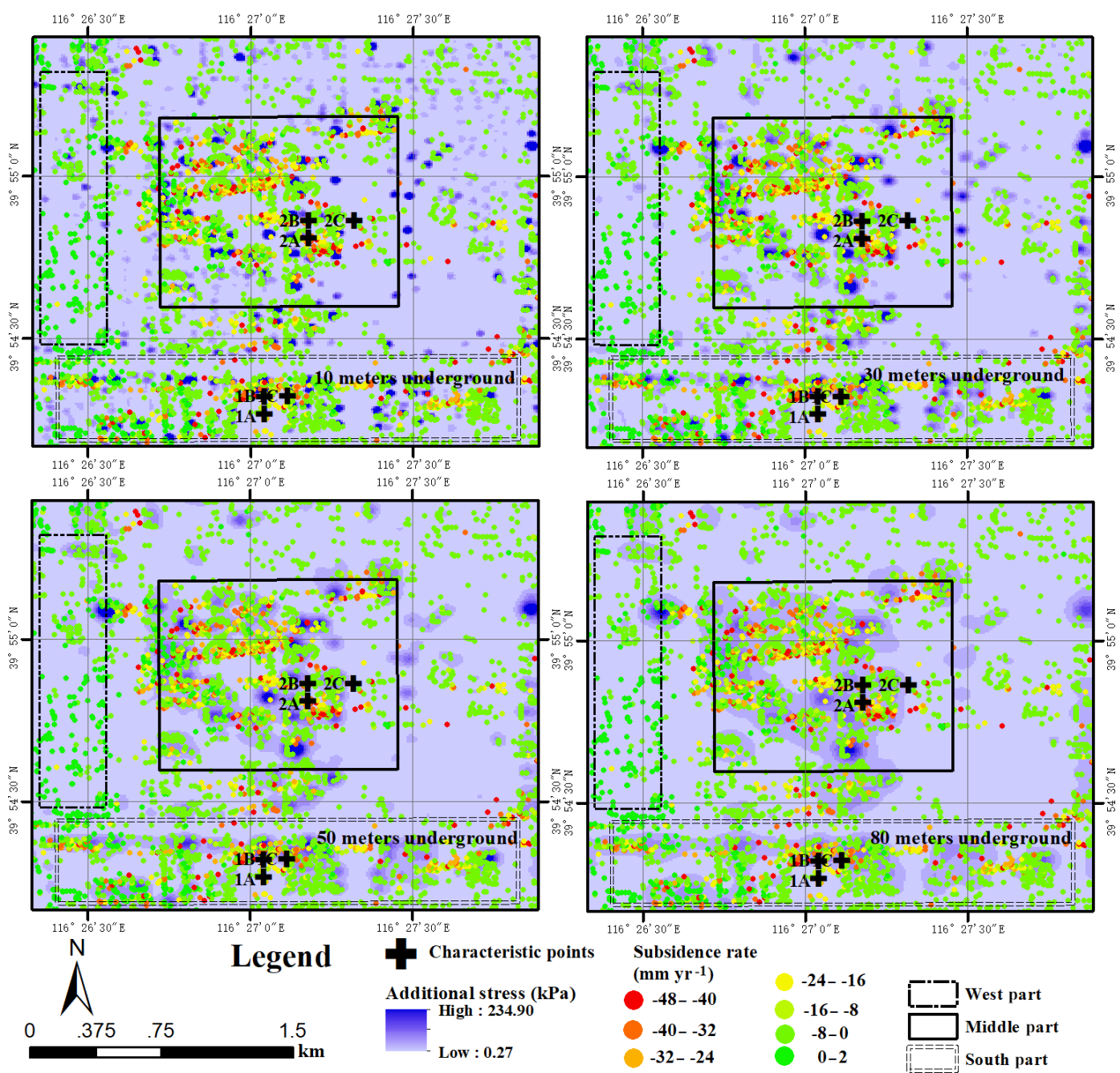

Figure 2. Land subsidence rate map and additional stress derived from building loads at different depths in the Central Business District.

ing load on the land subsidence is expected to increase. The groundwater level has little variation due to the lowest water was extracted in this area during the period between 2003 and 2018. As a typical piedmont alluvial diluvial plain, Quaternary sediments are widely distributed in Beijing (Luo et al., 2019). Ranging from 100 to $110 \mathrm{~m}$, the thickness of the compressible layer in CBD is relatively uniform. Thus, uneven land subsidence is not likely caused by the geological environment in the study area.

Based on building information from 1702 buildings in CBD, additional stress derived from building loads provided by the Beijing Municipal Commission of Planning and Natural Resources was calculated using the method proposed by Boussinesq (Eq. 1).

$\sigma=\sum_{i=1}^{n} \frac{3 P_{i}}{2 \pi} \frac{\left(Z-Z_{i}\right)^{3}}{\left[\left(X-X_{i}\right)^{2}+\left(Y-Y_{i}\right)^{2}+\left(Z-Z_{i}\right)^{2}\right]^{5 / 2}}$

where $\sigma$ is the additional stress derived from the building loads of the grid point, $n$ is the number of buildings, and $P_{i}$ is the gravity of building $i . X, Y$ is the projection coordinate of a point in the grid along the longitude, latitude with dimensions in World Geodetic System 1984 (WGS84), respectively. And $Z$ is the depth of the point in the grid. $X_{i}, Y_{i}$ is the projection coordinate of building $i$ along the longitude, latitude with dimensions in WGS84, respectively, and $Z_{i}$ is the foundation depth of building $i$. Additional stress maps of the whole study area can be obtained by using the kriging interpolation tool provided by ArcGIS. We found that the maximum value of additional stress derived from building loads is $246.54 \mathrm{kPa}$, and the pressure derived from the gravity of soil above the depth is $1491.12 \mathrm{kPa}$ when the depth reaches $80 \mathrm{~m}$ underground. This result indicates that the depth of influence of additional stresses induced by building loads is $80 \mathrm{~m}$ in the CBD area. We also found that spatial distribution of land subsidence was generally consistent with that of additional stress. Figure 2 shows that the deformation rate varies from -5.9 to $2 \mathrm{~mm} \mathrm{yr}^{-1}$ in the west part of the study area, where the buildings generally have less than 4 floors 

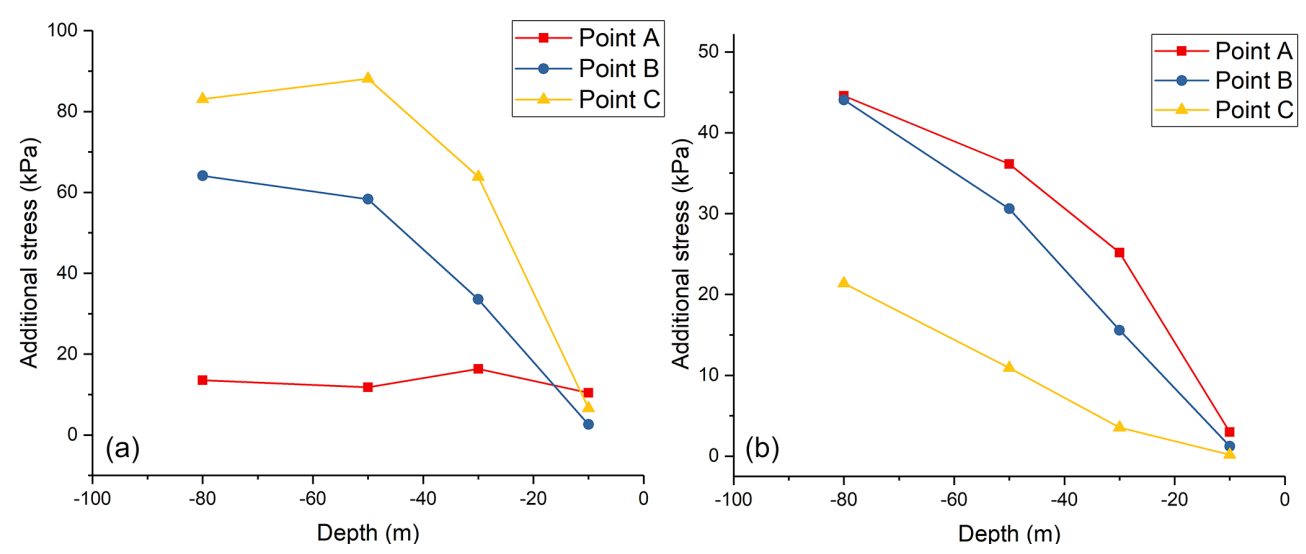

Figure 3. (a) Additional stress derived from building loads at different depths of Group 1 characteristic points. (b) Additional stress derived from building loads at different depths of Group 2 characteristic points.

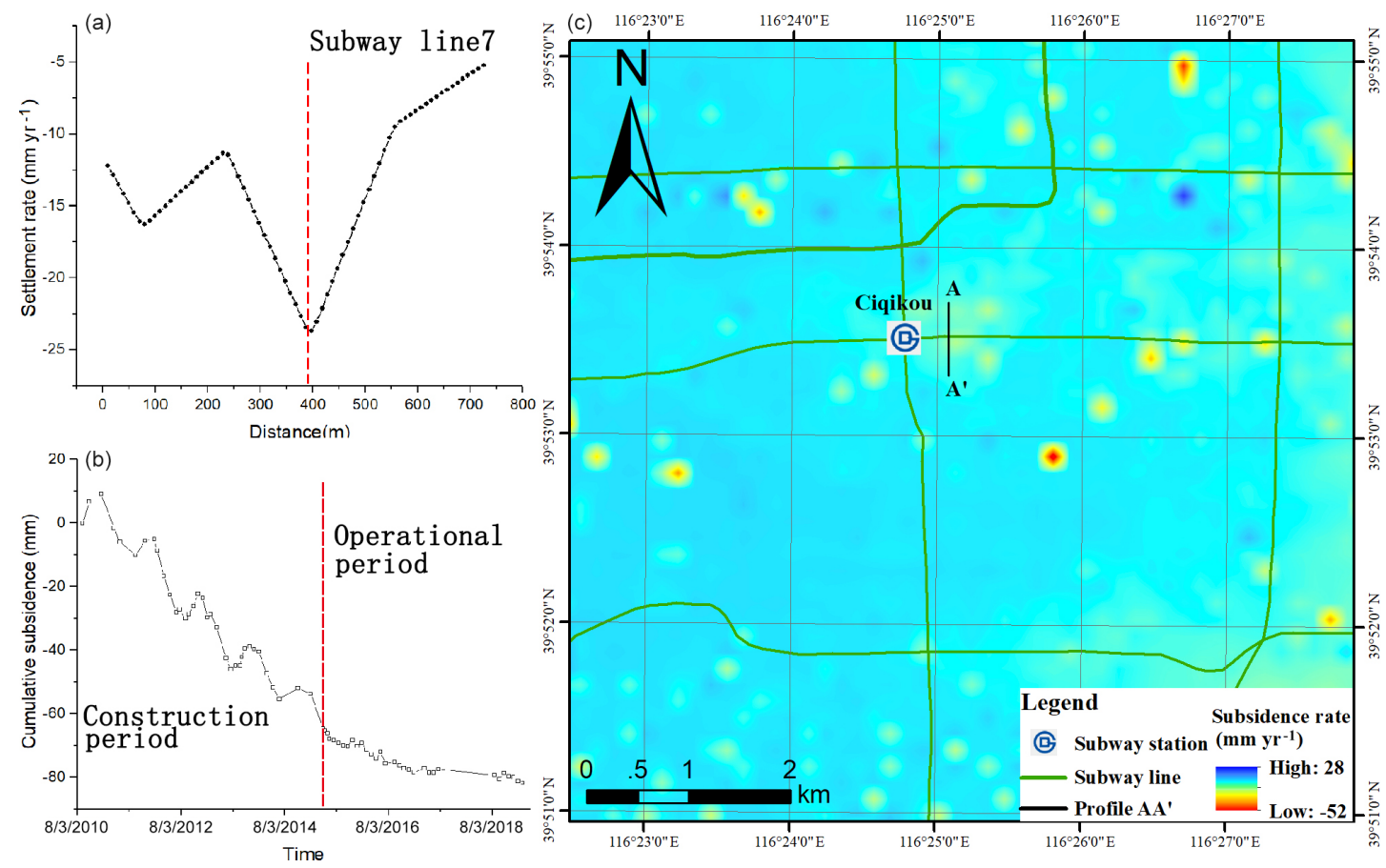

Figure 4. Average subsidence rete perpendicular to Beijing subway line 7 during 13 April 2010 to 10 December 2018. Subsidence rate profile AA' at Ciqikou station (a). Time series of coherent target above Ciqikou station (b).

and the value of additional stress is low, while the land subsidence rate varies from -47.9 to $-0.5 \mathrm{~mm} \mathrm{yr}^{-1}$ in the middle and south of the study area, where many skyscrapers have been built and the value of additional stress is relatively high. To further explore the relationship between additional stress derived from building loads and land subsidence rate, two groups of characteristic points were selected. Figure 3 shows additional stresses at different depths of the characteristic points. To some extent, we can conclude that a characteristic point with a higher additional stress has a greater deformation rate.

\section{Subsidence caused by construction and operation of metro}

In order to relieve traffic pressure in Beijing, 13 subway lines have been constructed between 2010 and 2018 . The velocity map described the extent and magnitude of surface deformation perpendicular to the metro lines due to the ground excavation. Figure 4 shown the subsidence perpendicular to Beijing subway line No. 7. By analyzing the subsidence rate profile AA', we find that the influence range of ground subsidence caused by metro construction is $200 \mathrm{~m}$ perpendicular to the Metro line and that the maximum land subsidence rate 
is $23.2 \mathrm{~mm} \mathrm{yr}^{-1}$. The subsidence extent is distinguished by the load of ground buildings. Under the same construction conditions, the subsidence over the built up area where has larger volume ratio is more significant than the general area.

Time series analysis of PS around Ciqikou station shows that the land subsidence rate has undergone a significant change during the construction and operation periods. The cumulative land subsidence caused by excavation activities reached $65 \mathrm{~mm}$ during the construction of Metro Line 7. The land subsidence rate decreases after Dec of 2014 and the cumulative settlement is $21 \mathrm{~mm}$ during the subway operation period.

\section{Conclusions}

Land subsidence caused by large-scale engineering construction in urban areas can be well monitored by using PS-InSAR technology and high resolution SAR data. The investigation of subsidence in CBD and assessment of subsidence perpendicular to subway line No. 7 have proved the validity of using high resolution images to monitor land subsidence of manmade objects and metro lines.

The results of both cases show that large-scale engineering construction will lead to significant land subsidence which may cause serious economic losses and hazards in city area. We can obtain the influence range of ground subsidence caused by large-scale engineering construction and the magnitude of land subsidence by mapping the temporal evolution of surface displacement occurring before and during construction. This can provide useful information for decision makers in urban planning.

Code and data availability. All data required to reproduce these findings cannot be shared at this time as the code also forms part of an ongoing study.

Author contributions. FL performed the experiments, analyzed the data and wrote the paper. HG and BC provided crucial guidance and support through the research. MG and CZ made important suggestions on data processing.

Competing interests. The authors declare that they have no conflict of interest.

Special issue statement. This article is part of the special issue "TISOLS: the Tenth International Symposium On Land Subsidence - living with subsidence". It is a result of the Tenth International Symposium on Land Subsidence, Delft, the Netherlands, 17-21 May 2021.
Financial support. This research has been supported by the National Natural Science Foundation of China (grant no. 41771455/D010702) and the National "Double-Class" Construction of University Projects (Beijing Youth Top Talent Project (grant no. BJJWZYJH01201910028032)).

\section{References}

Amelung, F., Galloway, D. L., Bell, J. W., Zebker, H. A., and Laczniak, R. J.: Sensing the ups and downs of Las Vegas: InSAR reveals structural control of land subsidence and aquifer-system deformation, Geology, 27, 483-486, https://doi.org/10.1130/00917613(1999)027<0483:stuado>2.3.co;2, 1999.

Buckley, S. M., Rosen, P. A., Hensley, S., and Tapley, B. D.: Land subsidence in Houston, Texas, measured by radar interferometry and constrained by extensometers, J. Geophys. Res.-Sol. Ea., 108, 243-251, https://doi.org/10.1029/2002JB001848, 2003.

Castellazzi, P., Garfias, J., Martel, R., Brouard, C., and Rivera, A.: InSAR to support sustainable urbanization over compacting aquifers:The case of Toluca Valley, Mexico, Int. J. Appl. Earth Obs., 63, 33-44, https://doi.org/10.1016/j.jag.2017.06.011, 2017.

Chen, B., Gong, H., Li, X., Lei, K., Duan, G., and Zhou, C.: Spatial correlation between land subsidence and urbanization in Beijing, China, Nat. Hazards, 75, 2637-2652, https://doi.org/10.1007/s11069-014-1451-6, 2015.

Chen, B., Gong, H., Li, X., Lei, K., Zhu, L., Gao, M., and Zhou, C.: Characterization and causes of land subsidence in Beijing, China, Int. J. Remote Sens., 38, 808-826, https://doi.org/10.1080/01431161.2016.1259674, 2017.

Du, Z., Ge, L., Ng, H. M., Zhu, Q., Yang, X., and Li, L: Correlating the subsidence pattern and land use in Bandung, Indonesia with both Sentinel-1/2 and ALOS-2 satellite images, Int. J. Appl. Earth Obs., 67, 54-68, https://doi.org/10.1016/j.jag.2018.01.001, 2018.

Ferretti, A., Prati, C., and Rocca, F.: Permanent scatterers in SAR interferometry, IEEE T. Geosci. Remote, 39, 8-20, https://doi.org/10.1109/36.898661, 2001.

Ferretti, A., Savio, G., Barzaghi, R., Borghi, A., Musazzi,S., Novali, F., Prati, C., and Rocca, F.: Submillimeter Accuracy of InSAR Time Series: Experimental Validation, IEEE T. Geosci. Remote, 45, 1142-1153, https://doi.org/10.1109/tgrs.2007.894440, 2007.

Galloway, D. L. and Burbey, T. J.: Review: Regional land subsidence accompanying groundwater extraction, Hydrogeol. J., 19, 1459-1486, https://doi.org/10.1007/s10040-011-0775-5, 2011.

Galloway, D. L., Erkens, G., Kuniansky, E. L., and Rowland, J. C.: Preface: Land subsidence processes, Hydrogeol. J., 24, 547-550, https://doi.org/10.1007/s10040-016-1386-y, 2016.

Gao, M., Gong, H., Chen, B., Li, X. Zhou, C., Shi, M., Si, Y., Chen, Z., and Duan, G.: Regional Land Subsidence Analysis in Eastern Beijing Plain by InSAR Time Series and Wavelet Transforms, Remote Sens., 10, 365-382, https://doi.org/10.3390/rs10030365, 2018.

Ge, D., Zhang, L., Li, M., Liu, B., and Wang, Y.: Beijing subway tunnelings and high-speed railway subsidence monitoring with PSInSAR and TerraSAR-X dat, Geoscience \& Remote Sensing Symposium, 10-15 July 2016, Beijing, China, IEEE, https://doi.org/10.1109/IGARSS.2016.7730796, 2016. 
Hooper, A., Zebker, H., Segall, P., and Kampes, B.: A new method for measuring deformation on volcanoes and other natural terrains using InSAR persistent scatterers, Geophys. Res. Lett., 31, 557-564, https://doi.org/10.1029/2004GL021737, 2004.

Jiao, S., Yu, J., Mials, A. S., Li, X., and Liu, L.: Assessing the Impact of Building Volume on Land Subsidence in the Central Business District of Beijing with SAR Tomography, Can. J. Remote Sens., 43, 177-193, https://doi.org/10.1080/07038992.2017.1291335, 2017.

Luo, Y., Chen, B., Lei, K., Hu, R., Ye, C., and Cui, W.: Optimum design of level monitoring points for land subsidence, B. Eng. Geol. Environ., 78, 5135-5146, https://doi.org/10.1007/s10064018-01442-6, 2019.

Ng, H. M., Ge, L., Li, X., Abidin, H. Z., Andreas, H., and Zhang, K.: Mapping land subsidence in Jakarta, Indonesia using persistent scatterer interferometry (PSI) technique with ALOS PALSAR, Int. J. Appl. Earth Obs., 18, 232-242, https://doi.org/10.1016/j.jag.2012.01.018, 2012.

Ortega-Guerrero, A., Rudolph, D. L., and Cherry, J. A.: Analysis of long-term land subsidence near Mexico City: Field investigations and predictive modeling, Water Resour. Res., 35, 33273341, https://doi.org/10.1029/1999wr900148, 1999.

Rosi, A., Tofani, V., Agostini, A., Tanteri, L., Stefanelli, C. T., Catani, F., and Casagli, N.: Subsidence mapping at regional scale using persistent scatters interferometry (PSI): The case of Tuscany region (Italy), Int. J. Appl. Earth Obs., 52, 328-337, https://doi.org/10.1016/j.jag.2016.07.003, 2016.
Sato, C., Haga, M., and Nishino, J.: Land subsidence and groundwater management in Tokyo, International Review for Environmental Strategies, 6, 404-424, 2006.

Solari, L., Ciampalini, A., Raspini, F., Bianchini, S., and Moretti, S.: PSInSAR Analysis in the Pisa Urban Area (Italy): A Case Study of Subsidence Related to Stratigraphical Factors and Urbanization, Remote Sens., 8, 120-137, https://doi.org/10.3390/rs8020120, 2016.

Strozzi, T., Delaloye, R., Poffet, D., Hansmann, J., and Loew, S.: Surface subsidence and uplift above a headrace tunnel in metamorphic basement rocks of the Swiss Alps as detected by satellite SAR interferometry, Remote Sens. Environ., 115, 1353-1360, https://doi.org/10.1016/j.rse.2011.02.001, 2011.

Uchida, Y.: Recent trends of land subsidence and groundwater management in Chikugo-Saga Plain, Journal of Groundwater Hydrology, 57, 19-27, https://doi.org/10.5917/jagh.57.19, 2015.

Zhao, Y. W. and Liu, C. L.: The role of load of clustered architecture on land subsidence, Hydrogeology \& Engineering Geology, 43, 6-15, https://doi.org/10.16030/j.cnki.issn.10003665.2016.06.25, 2016 (in Chinese).

Zhou, C., Gong, H., Chen, B., Li, X., Li, J., Wang, L., Gao, M., Si, Y., Guo, L., Shi, M., and Duan, G.: Quantifying the contribution of multiple factors to land subsidence in the Beijing Plain, China with machine learning technology, Geomorphology, 335, 48-61, https://doi.org/10.1016/j.geomorph.2019.03.017, 2019. 